\title{
Customer Service Providers' Attitudes Relating to Customer Service and Customer Satisfaction in the Customer-Server Exchange
}

\author{
Alex M. Susskind* \\ Cornell University \\ K. Michele Kacmar \\ Florida State University \\ Carl P. Borchgrevink \\ Michigan State University
}

June 8, 2001

\begin{abstract}
Author Note
Alex M. Susskind, School of Hotel Administration, Cornell University; K. Michele Kacmar, Department of Management, Florida State University; Carl P. Borchgrevink, School of Hospitality Business, Michigan State University.

This research was partially funded through a grant awarded to Alex M. Susskind by the Council on Research and Creativity at Florida State University while he was on their faculty.

We thank Georgia T. Chao and Daniel R. Ilgen for their useful comments on an earlier version of this article and Timothy R. Hinkin and J. Bruce Tracey for their suggestions pertaining to the data collection and analysis of our pilot study data.

*Correspondence concerning this article should be addressed to Alex M. Susskind, School of Hotel Administration, Cornell University, 250 Statler Hall, Ithaca, New York 14853. E-mail: ams76@cornell.edu
\end{abstract}




\begin{abstract}
The authors proposed and tested a model describing the relationship between customer service providers' perceptions and attitudes toward their service-related duties and their customers' perceptions of satisfaction with their service experiences. Results indicated that the perception of having standards for service delivery in an organization is strongly related to line-level employees' perceptions of support from coworkers and supervisors. Perceived support from coworkers was significantly related to service providers' customer orientation, whereas perceived support from supervisors showed a weaker relationship to a customer orientation. Ultimately, service providers' customer orientation was strongly related to customers' satisfaction with service. Finally, a set of post hoc analyses indicated that coworker and supervisory support explained a greater proportion of incremental variance in the model than did perceived organizational support alone.
\end{abstract}


Customer Service Providers' Attitudes Relating to Customer Service and Customer Satisfaction in the

\section{Customer-Server Exchange}

Service organizations and their employees differ from traditional manufacturing- and productbased organizations because they primarily deal with perishable, intangible products that are produced, presented, and consumed in a single episode or in a series of closely related episodes. Within each service episode the customers and service providers create and interpret expectations for the service episode and its outcomes (Ford, 2001) and determine whether expectations for service delivery have been met.

Noting the complexity of service delivery processes in service based organizations, researchers are increasingly paying attention to the study of employees responsible for front-line interaction with customers. Organizational issues, such as employees' reactions to customer service episodes (Bitner, Booms, \& Mohr, 1994), service or customer orientation (Brady \& Cronin, 2001), and the organizational factors that influence customer service processes and perceptions of a climate for service (Schneider, White, \& Paul, 1998), are now being addressed.

Customer service is an organizational behavior that is cocreated by three organizational constituents: management or ownership, coworkers, and customers. Ford and Etienne (1994) described how influences from these three constituents can affect service provider behavior during service encounters. Specifically, Ford and Etienne referred to customer variables, such as demographics or behavior; service provider variables, such as demographics, behavior, mood, and affect; and contextual variables, such as the organizational environment, structure, leadership, and coworkers. Similarly, in reference to a climate for service, Schneider et al. (1998) presented foundation issues as "contextual factors that sustain work behavior" (p. 151) and described the support needed to effectively perform service-related duties.

To explain how service constituents might react to service experiences, Hogan, Hogan, and Busch (1984) introduced the term service orientation to represent "a set of attitudes and behaviors that affects the staff of any organization and its customers" (p. 167). Brady and Cronin (2001) presented a model highlighting the extent to which service employees' customer orientation is related to consumers' 
perceptions of a service organization's performance, showing that elements of employee performance, physical goods quality, and the servicescape quality influenced consumers' perceptions of overall service quality. Likewise, Schneider et al. (1998) presented customer orientation as a service practice that assesses "the degree to which an organization emphasizes, in multiple ways, meeting customer needs and expectations for service quality" (p. 153), indicating that employees delivering service on the front lines have an influence on how customers' view their experience with services. We know less about what specifically drives or supports customer service behavior and about how service-oriented behavior and attitudes among service-based employees ultimately translates into customer satisfaction.

\section{Customer Service Processes and Outcomes}

In an effort to shed light on this underresearched area, we developed and tested Figure 1. The model outlined in Figure 1 begins with employees' perceptions of organizational standards for service delivery. Standards for service delivery are presented as an antecedent to employees' perceptions of coworker and supervisory support. Employees' perceived coworker and supervisory support are presented as antecedents of service workers' customer orientation. Front-line service workers' customer orientation is presented as an antecedent of customers' reported satisfaction with service. In the sections that follow, we define the constructs shown in Figure 1 and provide theoretical support for the links between them.

\section{Standards for Service Delivery}

Litwin and Stringer (1968) identified organizational standards as a key influence on individuals' behavior in organizations and defined standards as consisting of organizational members' perceptions of (a) organizational goals and objectives, (b) managerial expectations for job performance, and (c) the implicit importance placed on those goals, objectives, and performance demands. Because managers of service-based organizations typically have less direct interaction with their customers than they do with their front-line employees (Schneider \& Bowen, 1993), front-line employees tend to be the direct link between an organization's goals and operational mission and the consumers they serve (Grisaffe, 2000). 
Because front-line service providers are a key element in the service delivery process, the standards dimension presented in this article represents the extent to which these employees believe that they are viewed as an important part of the service delivery process (Lewis, 1989) and that standards exist to guide, direct, and monitor the service delivery behaviors of both management and line-level employees.

Standards represent an important part of an organization's mission as they provide guidelines for how products or services are produced, delivered, and evaluated. Grisaffe (2000) indicated that managerial philosophies and values influence an organization's internal business practices, which, in turn, influence employee and customer interactions and behaviors. Armeli, Eisenberger, Fasolo, and Lynch (1998) described this contention from a social exchange framework (Blau, 1964), suggesting that perceptions of organizational support are likely to be stronger when employees believe they are acting consistently with organizational standards. Schmit and Allscheid (1995) also identified service standards as a key part of an organization's service climate because they positively influence employees' affect and performance.

Whereas standards that foster a climate for positive servicerelated behaviors will likely positively influence said behaviors, having standards in place is not a guarantee that service providers will "walk the talk" when delivering service. For that reason, support functions are presented as mediators of the relationship between standards for service and customer orientation, because standards likely prompt supportive behavior from the members of the organization, creating a supportive climate for service.

\section{Perceptions of Support}

Eisenberger, Huntington, Hutchinson, and Sowa (1986) defined organizational support as a set of perceptions that gauge the extent to which employees perceive their organization as being concerned for or committed to their well-being. Organizational support has been shown to influence employee performance in a number of ways. Eisenberger, Fasolo, and Davis-LaMastro (1990) reported that perceptions of organizational support were positively related to employee attendance and job performance, just as Schmit and Allscheid (1995) indicated that a supportive climate for service 
influenced behavioral intentions to provide service and ultimately influenced customer satisfaction and perceived service or product quality. A social exchange perspective (Blau, 1964) would suggest that the exchange of resources (in this case support) prompts a sense of obligation, on the part of the recipient of the support, to reciprocate in kind (Eisenberger, Cummings, Armeli, \& Lynch, 1997). If standards for service delivery set the stage for desired performance, then those individuals involved in the service process should use the existing standards as a guide to offer support to others to ensure that the appropriate service-related behaviors are ultimately delivered to the customers.

Given the broad range of support elements present in service-based organizations, where employees, customers, and management each take part in the service process, it is necessary to clarify organizational support functions in service-based organizations. In their description of a climate for service, Schneider et al. (1998) made a similar clarification through their presentation of foundation issues. They showed support coming from internal constituents (e.g., other departments) or general facilitative conditions (e.g., supervisor support), which ultimately influenced customers' perceptions of service quality. We view the separation of support functions as necessary and suggest that it will lead to a better description of customer service processes as coworkers and supervisors likely play different, but important, support roles in the customer-service exchange (CSX).

Our proposed division of organizational support into coworker and supervisor support extends the work of Eisenberger and his colleagues $(1986,1990,1997)$ into service-based contexts and focuses on employees' perceptions of support to perform their service-related duties rather than their general perceptions of the organization's concern for their well-being. In service-based organizations, the majority of customer-server interactions occur on the front lines as part of product or service delivery and consumption. This is likely the key distinction that makes support functions in service-based organizations unique.

Coworker support. We defined coworker support as the extent to which employees believe their coworkers are willing to provide them with work-related assistance to aid in the execution of their service-based duties. In most instances, coworkers' perceived support is vital to the accomplishment of 
work-related tasks but influences more than just tangible issues, such as morale. Coworker support (whether formal or informal in nature) is usually void of hierarchical differences, likely supplements formal support offered from supervisors and managers, and should be based on the espoused organizational standards for service delivery.

Supervisory support. Supervisory support is defined as individuals' beliefs that supervisors offer them work-related assistance to aid in the performance of their job. Employees receiving adequate support from their superiors will most likely view that support as an organizational function, consistent with Wayne, Shore, and Liden's (1997) finding that the quality of leader- member exchange has a strong effect on perceived organizational support offered to coworkers.

In the hypothesized model we proposed that standards act as a prompt for support from both coworkers and supervisors to help ensure the delivery of service-related behavior to customers. This suggests that standards motivate service providers to perform supportive behaviors in the execution of their duties.

\section{Customer Orientation}

Kelley (1992) defined customer orientation as the importance that service providers place on their customers' needs relating to service offerings and the extent to which service providers are willing to put forth time and effort to satisfy their customers. Customer orientation is a product of the customer service process; is influenced by exposure to and relationships with the customers, coworkers, and superiors involved in the service process (Brady \& Cronin, 2001); and represents a service provider's level of commitment to customers.

Service providers who routinely modify their service delivery to anticipate and meet the needs of their customers are described as customer oriented. For example, customer-oriented behavior might involve offering customers more choices and suggestions to enhance their service experience (Ford, 2001; Surprenant \& Solomon, 1987). When service providers receive support from their coworkers and superiors while performing their duties, it will likely lead to a stronger commitment to the service process, 
particularly when the supportive actions of others are based on the organization's standards for service delivery.

\section{Customer Satisfaction}

How customers react to service experiences is a main concern for people in the business of providing service. Consequently, a large volume of research has examined the influences and outcomes of service experiences. In this investigation, we specifically limit our analyses to examine the organizational level relationship between customers' reports of satisfaction with their service experiences and service providers' perceptions of their servicerelated duties, connecting customer service employees' perceptions of service encounters to customers' evaluations of service experiences within the same organization. To date, a limited number of studies have examined the connection between employee and customer perceptions of the service process (e.g., Brady \& Cronin, 2001; Johnson, 1996). We add to the existing body of work in this area by examining how service providers' perceptions of standards for service delivery, along with multidimensional support functions, and customer orientation are ultimately related to customers' satisfaction with service delivery in the organization.

As noted by Bitner et al. (1994), role theory is useful in describing the connections between employees' and customers' perceptions. Role theory suggests that when both parties conceptually understand and accept their role in the CSX, their expectations are more likely to be met or exceeded. As either customers or service providers sense a process violation, their satisfaction with the experience is likely to be negatively influenced as individuals involved in the service episode attempt to reconcile their perceived differences.

Research by Schneider, Wheeler, and Cox (1992) and Schneider et al. (1998) indicated that service providers' positive perceptions of service processes are linked with customers' positive perceptions. When service providers have a high level of commitment to their role in the service process, realized as a customer orientation, they are more likely to be motivated to consistently offer their customers a level of service that is satisfying. 


\section{Method}

\section{Participants and Procedure}

A total of 390 line-level service workers employed in service-based facilities in the Midwest were sampled for this investigation. The line-level participants were $43 \%$ male and 57\% female, were between the ages of 15 and 56 years (M 24.55), had worked for their organization at the time of survey administration for an average of 2.9 years, and represented 37 different service-based organizations. To assess customer satisfaction in the organizations, an average of 10 customers were sampled from 28 of the 37 organizations that allowed us access to their customers following service experiences. In total, we collected 269 usable responses from customers and ultimately had a listwise sample of 354 line-level respondents across 26 of the 28 organizations once the customer satisfaction scores were aggregated, matched, and deemed reliable at the organizational level, with an average of 13.85 employees surveyed from each of the 26 organizations.

Line-level employees were approached by the researchers and asked to complete a questionnaire while at work. To minimize their participant burden and to avoid interference with the normal performance of their jobs, the participants were given the option of either completing the questionnaire at the time of introduction or having the researchers return later in the day to collect the completed questionnaire. Shortly following the collection of the employee data, the customer satisfaction data were collected from the organizations. We did not match specific customers to the specific employees who served them because most of the organizations sampled regularly used multiple employees to serve their customers in any given service episode.

\section{Measurement and Analyses}

Pilot study. We surveyed 400 master's of business administration students to conduct the pilot study. The participants included 192 (48\%) men and 208 (52\%) women, with an average age of 28.57 years. We generated 33 survey items to represent the four proposed dimensions of standards for service delivery (11 items), coworker support (7 items), supervisor support ( 7 items), and customer orientation (8 
items). Respondents were asked to rate the 33 individual survey items against the set of the four construct definitions. The ratings were evaluated statistically by using one-way analysis of variance (ANOVA). If a set of items was consistently rated as matching the proposed a priori construct definition, it was assumed to be consistent with the construct definition (Hinkin \& Tracey, 1999). Duncan's multiple range tests were used to detect significant differences between the survey items and their match to the four construct definitions at the $p=.05$ level. The analyses suggested that we retain 4 items to represent standards for service delivery, 3 items to represent coworker support, 4 items to represent supervisor support, and 5 items to represent customer orientation.

Line-level employees. Using the survey measures yielded from the pilot study (see Appendix A for the items used), we evaluated the line-level employees' perceptions of standards for service delivery, coworker support, supervisory support, and customer orientation. The participants were asked to indicate their level of agreement with each question on a 5-choice metric with anchors ranging from $1=$ strongly disagree to $5=$ strongly agree.

Confirmatory factor analyses. Acknowledging Anderson and Gerbing's (1988) recommended two-step approach to model testing, we assessed the four-factor measurement model for fit independently from the assessment of the structural model. In the analyses, the factors were permitted to correlate. To address concerns over the sensitivity of chisquare tests to sample size, we used a covariance matrix as input and examined the comparative fit index (CFI) and the root-mean-square residual (RMR) because these fit indices have been reported to be most suited to small samples (Bentler, 1990; Hu \& Bentler, 1998). The results from our LISREL 8.12a (Joreskog \& Sorböm, 1993) analyses yielded a RMR of .05 and a CFI of .95, supporting the factor structure yielded from the pilot study described above.

Customers. Customer satisfaction was measured by using six items (see Appendix A) developed specifically for this investigation and by using the same five-choice response categories. The responses to the customer satisfaction questions were aggregated to the organizational level, producing an organizational mean ranging from $1.40(\mathrm{SD}=0.30)$ to $4.57(\mathrm{SD}=0.39)$. The measure was reliable $(\alpha$ 
$=.96$ ) and yielded a single-factor solution using exploratory factor analysis, explaining $82.46 \%$ of the variance. This measure was not examined in the pilot study.

Data aggregation. To determine the appropriateness of testing our hypotheses at the organizational level, we examined the intra-class correlations (ICC[1] and ICC[2]) of the variables in the model. In this case, ICC(1) estimated the proportion of variance in the participants that could be accounted for through differences in their organizational affiliation, whereas $\operatorname{ICC}(2)$ estimated the reliability at the group level (James, 1982). Although the ICC(1) levels fell within the recommended range of values, the $\mathrm{ICC}(2)$ values were low but were mainly consistent with estimates reported in prior studies of this type as follows (cf. Schneider et al., 1998): $\operatorname{ICC}(1)=.13$ and $\operatorname{ICC}(2)=.50$ for standards for service delivery, $\operatorname{ICC}(1)=.16$ and $\operatorname{ICC}(2)=.59$ for coworker support, $\operatorname{ICC}(1)=.15$ and $\operatorname{ICC}(2)=.56$ for supervisor support, and $\operatorname{ICC}(1)=.31$ and $\operatorname{ICC}(2)=.83$ for customer orientation.

To offer sufficient support to aggregate these variables to the organizational level, we examined the $r_{w g(j)}$ statistic (James, Demaree, \& Wolf, 1984) to determine within-organization agreement. The $r_{w g(j)}$ was computed for each scale in each of the 28 organizations. During an examination of the withinorganization agreement, the analyses revealed that 2 of the 28 organizations did not show sufficient agreement on the supervisor support and standards for service delivery scales. Thus, 2 organizations were excluded from the sample. The employees' responses from the remaining 26 organizations that aggregated to the organizational level exceeded the recommended cutoff of .60 offered by James (1982) as follows: $r_{w g(4)}=.69$ for standards for service delivery, $r_{w g(3)}=.74$ for coworker support, $r_{w g(4)}=$ .91 for supervisor support, and $r_{w g(5)}=.90$ for customer orientation. Likewise, the customer satisfaction data yielded from the 269 customers from the 26 organizations were well suited to aggregation, indicating a high level of agreement (ICC[1] .40, ICC[2] .96, and $\left.r_{w g(6)}=.96\right)$. The descriptive statistics and correlations of the variables aggregated to the organizational level are reported in Table 1. 
Structural equation modeling. The model presented as Figure 1 was estimated by using LISREL 8.12a (Joreskog \& Sorböm, 1993), using a covariance matrix as input. The path coefficients reported in Figure 2 are completely standardized. To test the path model we applied the recommendations offered by Hayduk (1987). By default, the error terms were permitted to correlate and no other relationships other than those specified in the path diagram were permitted to correlate in the structural analyses. To compensate for measurement error in the scale values within the path model, the paths from the latent variables to the indicators were set to the square root of the scale reliability at the group level.

Additionally, the error variance was set to equal the variance of the scale multiplied by one minus the reliability. These procedures fix the proportion of error variance assigned to each factor on the basis of the scale reliabilities and the relevant variance associated with each factor (Hayduk, 1987). In addition, to ensure that the hypothesized model was superior to alternative models of the data, we examined several alternative models.

\section{Results}

\section{Test of the Hypothesized Model}

The initial model estimation revealed that the hypothesized model produced a very good fit to the data, $\chi^{2}(5, N=26)=5.19, p=.39$. The fit statistics confirmed a nonsignificant chi-square result $(\mathrm{CFI}=$ $1.00, \mathrm{RMR}=.02$ ), suggesting that the hypothesized model fit the data well. As predicted, all of the paths were positive.

\section{Post Hoc Analyses}

Two alternative-mediating models. To determine whether Figure 2 is the best approximation of the data, two alternative models were tested. Alternative Model 1 assessed whether the two support functions should be treated as endogenous or exogenous variables, and Alternative Model 2 examined whether standards were partially mediated by the support functions. To test Alternative Model 1, the relationships between coworker and supervisory support and standards were reversed, removing the direct link from the support functions and customer orientation and placing standards as the mediator variable 
between the coworker and supervisory support and customer orientation. To test for the partial mediation of the support functions in Alternative Model 2, a direct link was added between standards and customer orientation. The results revealed that although both Alternative Model $1, \chi^{2}=2(5, N=26)=9.10, p=$ $.11, \mathrm{CFI}=.90, \mathrm{RMR}=.04$, and Alternative Model $2, \chi^{2}=2(4, N=26)=5.65, p=.23, \mathrm{CFI}=.96, \mathrm{RMR}$ $=.02$, fit the data well, the hypothesized model presented as Figure 2 best captures the data in this study. An alternative moderating model. It is also possible that the support functions act as moderating influences between standards for service and customer orientation. To test this possibility, we followed the recommendations of Baron and Kenny (1986) and treated customer orientation as the sole dependent variable, leaving the relationship between customer orientation and customer satisfaction out of the analyses. A four-step regression equation was used to test for interactive effects. On the first step, standards for service was entered. On the second step, supervisor support was added. On the third step, coworker support was added to the equation, and on the final step, the interaction terms of Standards X Coworker Support and Standards X Supervisor Support were added to the equation. As the results in Table 2 illustrate, the relationship between standards for service and customer orientation is not significantly enhanced by the addition of coworker support and supervisory support as moderators.

Together, these post hoc analyses indicate that full moderation or partial mediation by the support functions in the model does not offer a better fit to the data than the hypothesized model presented in Figure 2. It should be noted that with the low power associated with a small sample size, it remains possible that the effects of moderation are somewhat suppressed.

Influence of perceived organizational support. An alternative model using the single dimension of perceived organizational support (Eisenberger et al., 1986) in place of coworker support and supervisor support was tested to empirically assess the utility of splitting perceptions of support into two dimensions. As prior research would suggest (cf. Eisenberger et al., 1990), the alternative model fit the data well, $\chi^{2}(3, \mathrm{~N}=26)=3.98, p=.26, \mathrm{CFI}=.97, \mathrm{RMR} .03$, but did not demonstrate a superior fit to the hypothesized model presented as Figure 2. In Appendix B we present the details of this post hoc examination. 


\section{Discussion}

Our results suggest that among 26 different service-based organizations, employees and customers reacted similarly to the service process they cocreated. Generally, employees perceiving high levels of standards for service delivery indicated a strong presence of both coworker and supervisor support, which was then related to their perceptions of a customer orientation. Ultimately, in the organizations where employees reported a high level of customer orientation, the customers reported a higher level of customer satisfaction with service. From our findings a clear pattern emerged. Customer satisfaction was related directly and indirectly to a number of service-related factors, some of which are under management's control and others of which rest solely with the front-line service providers. Our findings build on Schneider and colleagues' (1998) work examining service-based organizations and Eisenberger and colleagues' $(1986,1990,1997)$ work examining the influence of organizational support on performance.

The tests of the fully mediated path model presented in Figure 2 revealed four notable findings. First, standards for service shape the way individuals view their service-related duties. When employees become conscious of the organizational goals for service and the role that standards play in that process, they will be better able to direct and influence the service process to meet those goals. In the model, support functions were shown to be mediators of the relationship between standards for service and customer orientation, indicating that the mere existence of standards is no guarantee that standards will be effectuated at the line level. It is the support and guidance based on those standards that will most likely lead to a customer orientation. When standards for service delivery were high, our findings indicated that employees reported higher levels of support from both coworkers and supervisors. It should be noted, however, that the influence of standards on supervisor support was stronger than the influence on coworker support. What this suggests is that for standards for service to be realized, they need to be directed through organizational efforts first and through coworkers second. This finding is consistent with the works of Levinson (1965) and Eisenberger et al. (1990), who indicated that organizational support should be consistent with and based on an organization's operational goals and objectives. 
Second, we also discovered that coworker support was significantly related to customer orientation, whereas supervisor support was not. These findings suggest that the perceived presence of supportive coworkers in a service environment leads employees to a higher level of commitment to their customers. Our findings indicate that it is important to have a supportive group of peers by your side to help you perform service-related duties. It was particularly interesting that supervisory support did not have the same influence on customer orientation as did coworker support, given its strong connection to standards for service delivery. It could be that coworker support contains unique elements that do not surface in superior-subordinate supportive behaviors. This finding also supports the contention that linelevel employees, in performing their service-related duties, interact more with customers than do managers, making coworkers the group closest to them in the CSX. The observed relationships involving coworker and supervisor support indicate that organizational members view support from coworkers differently than they view support from their supervisors, confirming our contention that perceptions of support in a service environment come from multiple sources (cf. Schmit \& Allscheid, 1995) and are based on a social exchange framework (Blau, 1964). It also can be inferred from these findings that standards lay the foundation for supportive behaviors from both coworkers and superiors, but that each type of support plays a different function in the service delivery process.

Our approach is a departure from the applications of support offered by Eisenberger and colleagues $(1986,1990)$. Coworker and supervisor support, as presented here, does not measure the employees' sense of the organization's commitment to their personal well-being but rather the extent to which individuals believe that their peers and supervisors provide support for their workrelated efforts. We believe our focus on work-related support rather than general affect is an important contribution to an increased understanding of front-line service workers.

Third, customer satisfaction with service was notably related to high levels of customer orientation as reported by the servicebased employees from the organizations we examined. Customer satisfaction with an organizations' service was positively associated with the employees' customer orientation. It seems almost too simplistic to mention, but our findings suggest that service providers who 
are committed to their customers tend to make their customers happy more often than service providers who are not committed to their customers. Consistent with role theory, these findings suggest that as customer-oriented employees fulfill their role as service providers, they offer their customers appropriate service, which is then strongly related to customers' satisfaction as the recipients of service. This finding suggests future research is needed to further establish how other elements, such as job affect and pay, may also influence customer orientation.

Last, by testing several alternative models, we were able to illustrate that the hypothesized model is a sound representation of the data. However, Alternative Model 2, the fully moderated model, and the alternative perceived organizational support (POS) model each demonstrated some strengths that should not be summarily dismissed. In future investigations, these alternative models should be retested to ensure that the model shown in Figure 2 best represents service workers' and customers' reactions in the CSX. In addition to our findings about customer satisfaction, there are also several broader implications of this work regarding the levels of analysis used. The analyses revealed that a consistent service-based organizational climate or culture existed across 26 different service-based organizations composed of individual responses from a set of service providers and customers. These findings highlight the existence of a set of shared meanings among organizational members (including customers) and more generally across service-based organizations. Three basic levels were common among the 26 organizations represented here.

First, the organizations in this study were sampled from the domain of service organizations. Service organizations can differ on the basis of the degree of customer contact (high or low) or their service type (such as restaurants, retail shops, or banks) representing the broadest level of conceptualization among the organizations. Second, each organization, within the domain of service organizations, had a set of values, procedures, and processes that guided and directed its existence in the organizational domain, representing yet a narrower view of the organizations. Third, each organization was then composed of a set of service providers and customers that carried out the day-to-day activities. Of the variables measured at the employee level, customer orientation showed the strongest level of 
within-organization agreement. This finding suggests that although standards and support functions are important elements in the CSX, they are perceived as being present in the organizations in varying degrees. It is reassuring that the front-line employees in the service organizations we sampled agree with great consistency that customer orientation is a stable factor in the service delivery process.

We believe that the data represented here resemble a strong positive etic relationship (Chao, 2000; Leung \& Bond, 1989). A positive etic relationship exists when similar relationships can be observed across multiple levels in the sample — in this case within and between service-based organizations. Because the service providers' and customers' responses were consistent, they could be aggregated and analyzed at the organizational level. The analysis of the data at the individual and organizational levels suggested that the proposed model was consistent beyond the organizational level across the 26 organizations in the sample. This set of analyses connected specific individual-level responses to the organizational level and ultimately to service organizations in general, showing that an organizational climate for service existed at multiple levels.

The findings of this study highlight several directions for future research. First, it would be useful to assess the relationship between standards, support, customer orientation, customer satisfaction, and additional measures of performance beyond customer satisfaction, such as employee performance or firm performance. Second, it would be prudent to secure a matched sample of employee, managerial, and customer responses to test this model entirely at the individual level of analysis to confirm that the appropriate level of analysis was applied to the model. Third, although consistent in size with studies of groups, networks, and meta-analyses (Hunter \& Schmidt, 1992) that appear in the literature, our sample of organizations was small. Thus, future investigations should increase the sample size in the analyses, whether aggregating the data to the organizational level or examining the data at the individual level.

In conclusion, given the animated nature of the customer service process, developing a better understanding of the constituents involved with the CSX is crucial to the alignment of an organization's operational goals and their customers' needs and expectations. Our findings suggest that maintaining a service-oriented workforce is one way to meet those needs. 
Table 1. Descriptive Statistics and Correlations From the Final Aggregated Scales at the Organizational Level.

\begin{tabular}{lccccccc}
\hline \multicolumn{1}{c}{ Variable } & $M$ & $S D$ & 1 & 2 & 3 & 4 & 5 \\
\hline 1. Standards for service delivery & 3.64 & 0.38 & $(.68)$ & & & & \\
2. Coworker support & 3.77 & 0.43 & $.43^{*}$ & $(.74)$ & & & \\
3. Supervisor support & 3.47 & 0.47 & $.64^{* *}$ & .08 & $(.68)$ & & \\
4. Customer orientation & 4.23 & 0.39 & $.49^{*}$ & $.63^{* *}$ & .24 & $(.91)$ & \\
5. Customer satisfaction & 3.38 & 1.03 & $.48^{*}$ & $.59^{* *}$ & .30 & $.62^{* *}$ & $(.96)$ \\
\hline
\end{tabular}

Note. $N=26$. James et al. (1984) $r_{w g(j)}$ aggregation statistic is presented along the diagonal in parentheses and represents the average across the 26 organizations.

$* p<.05 . * * p<.01$. 
Table 2. Regression Results for the Alternative Moderating Model

\begin{tabular}{|c|c|c|c|c|c|c|}
\hline Variable & $\beta$ & $b$ & $t$ & $p$ & $R^{2}$ & $\Delta R^{2}$ \\
\hline \multicolumn{7}{|l|}{ Step 1} \\
\hline Standards for service delivery & .51 & .50 & 2.78 & .01 & - & - \\
\hline$F(1,24)=7.77^{* *}$ & - & - & - & - & .24 & - \\
\hline \multicolumn{7}{|l|}{ Step 2} \\
\hline Supervisor support & -.01 & -.12 & -0.51 & .62 & - & - \\
\hline Standards for service delivery & .59 & .57 & 2.44 & .02 & - & - \\
\hline$F(2,23)=3.89^{*}$ & - & - & - & - & .25 & .01 \\
\hline \multicolumn{7}{|l|}{ Step 3} \\
\hline Coworker support & .48 & .53 & 2.93 & .01 & - & - \\
\hline Supervisor support & .00 & .06 & 0.30 & .78 & - & - \\
\hline Standards for service delivery & .24 & .23 & 0.97 & .34 & - & - \\
\hline$F(3,22)=6.31^{* *}$ & - & - & - & - & .46 & .21 \\
\hline \multicolumn{7}{|l|}{ Step 4} \\
\hline \multicolumn{7}{|l|}{ Interactions } \\
\hline Standards $\times$ Coworker & 0.84 & 5.28 & 2.45 & .02 & - & - \\
\hline Standards $\times$ Supervisor & -0.41 & -2.90 & -1.37 & .19 & - & - \\
\hline Coworker support & -2.66 & -2.94 & -2.11 & .05 & - & - \\
\hline Supervisor support & 1.57 & 1.90 & 1.40 & .18 & - & - \\
\hline Standards for service delivery & -1.27 & 1.57 & -0.81 & .43 & - & - \\
\hline$F(5,20)=6.34^{* * *}$ & - & - & - & - & .61 & .15 \\
\hline
\end{tabular}

Note. Dependent variable: Customer orientation. Dashes indicate that data were not applicable.

$* p<.05 . * * p<01 . * * * p<.001$ 


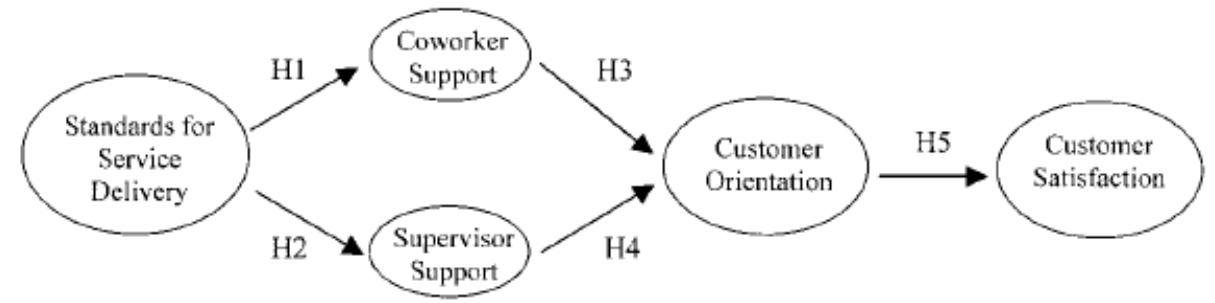

Figure 1. Hypothesized model of the customer service process and organizational outcomes. $\mathbf{H}=$ Hypothesis 


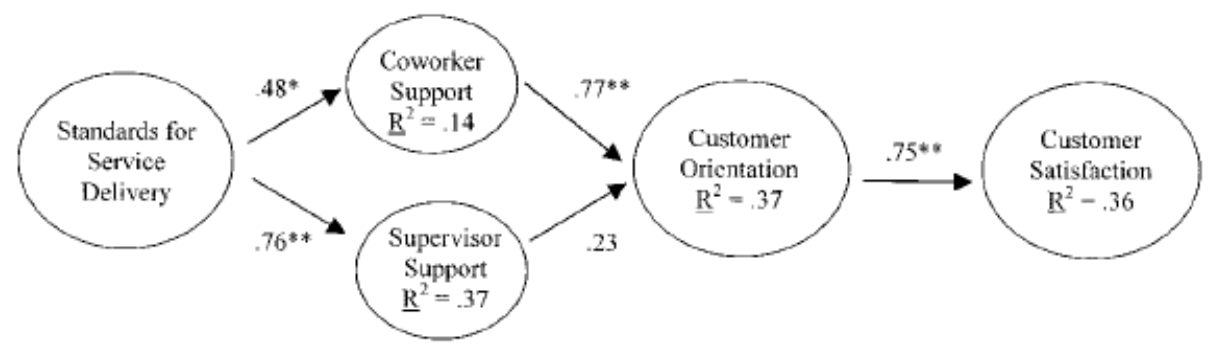

Figure 2. Estimated model of customer service process and organizational outcomes. Path coefficients presented are completely standardized, and all links in the model were tested at the organizational level. $* p<.05$. ** $p<01$. 


\section{References}

Anderson, J. C., \& Gerbing, D. W. (1988). Structural equation modeling in practice: A review and recommended two-step approach. Psychological Bulletin, 103, 411-423.

Armeli, S., Eisenberger, R., Fasolo, P., \& Lynch, P. (1998). Perceived organizational support and police performance: The moderating influence of socioemotional needs. Journal of Applied Psychology, 83, 288-297.

Baron, R. M., \& Kenny, D. A. (1986). The moderator-mediator variable distinction in social psychological research: Conceptual, strategic, and statistical considerations. Journal of Personality and Social Psychology, 51, 1173-1182.

Bentler, P. M. (1990). Comparative fit indices in structural models. Psychological Bulletin, 88, 588-606.

Bitner, M. J., Booms, B. H., \& Mohr, L. A. (1994). Critical service encounters: The employee's viewpoint. Journal of Marketing, 58, 95-106.

Blau, P. M. (1964). Exchange and power in social life. New York: Wiley.

Brady, M. K., \& Cronin, J. J. (2001). Customer orientation: Effects on customer service perceptions and outcome behaviors. Journal of Service Research, 3, 241-251.

Chao, G. T. (2000). Multilevel issues and culture: An integrative view. In K. J. Klein \& S. W. J. Kozlowski (Eds.), Multilevel theory, research, and methods in organizations (pp. 308-346). San Francisco: Jossey-Bass.

Eisenberger, R., Cummings, J., Armeli, S., \& Lynch, P. (1997). Perceived organizational support, discretionary treatment, and job satisfaction. Journal of Applied Psychology, 82, 812-820.

Eisenberger, R., Fasolo, P., \& Davis-LaMastro, V. (1990). Perceived organizational support and employee diligence, commitment, and innovation. Journal of Applied Psychology, 75, 51-59.

Eisenberger, R., Huntington, R., Hutchinson, S., \& Sowa, D. (1986). Perceived organizational support. Journal of Applied Psychology, 71, 500-507. 
Ford, W. S. Z. (2001). Customer expectations for interactions with service providers: Relationship versus encounter orientation and personalized service communication. Journal of Applied Communication Research, 29, 1-29.

Ford, W. S. Z., \& Etienne, C. N. (1994). Can I help you? A framework for interdisciplinary research on customer service encounters. Management Communication Quarterly, 7, 413-441.

Grisaffe, D. (2000). Putting customer satisfaction in its place: Broader organizational research perspectives versus measurement myopia. Journal of Consumer Satisfaction, Dissatisfaction, and Complaining Behavior, 13, 1-16.

Hayduk, L. A. (1987). Structural equation modeling with LISREL: Essentials and advances. Baltimore: Johns Hopkins University Press.

Hinkin, T. R., \& Tracey, J. B. (1999). An analysis of variance approach to content validation. Organizational Research Methods, 2, 175-186.

Hogan, J., Hogan, R., \& Busch, C. M. (1984). How to measure service orientation. Journal of Applied Psychology, 69, 167-173.

Hu, L., \& Bentler, P. M. (1998). Fit indices in covariance structure modeling: Sensitivity to underparameterized model misspecification. Psychological Methods, 3, 424-453.

Hunter, J. E., \& Schmidt, F. L. (1992). Methods of meta-analysis. Newbury Park, CA: Sage.

James, L. R. (1982). Aggregation bias estimates of perceptual agreement. Journal of Applied Psychology, 67, 219-229.

James, L. R., Demaree, R. G., \& Wolf, G. (1984). Estimating within-group interrater reliability with and without response bias. Journal of Applied Psychology, 69, 85-98.

Johnson, J. (1996). Linking employee perceptions to customer satisfaction. Personnel Psychology, 49, $831-852$.

Joreskog, K. G., \& Sorböm, D. (1993). LISREL for Windows 8.12a. Chicago: Scientific Software International. 
Kelley, S. W. (1992). Developing customer orientation among service employees. Journal of the Academy of Marketing Science, 20, 27-36.

Leung, K., \& Bond, M. H. (1989). On the empirical identification of dimensions for cross-cultural comparisons. Journal of Cross-Cultural Psychology, 20, 133-151.

Levinson, H. (1965). Reciprocation: The relationship between man and organization. Administrative Science Quarterly, 9, 370-390.

Lewis, R. C. (1989, November). Hospitality marketing: The internal approach. Cornell Hotel and Restaurant Administration Quarterly, 30, 41-45.

Litwin, G. H., \& Stringer, R. A., Jr. (1968). Motivation and organizational climate. Boston: Harvard University Graduate School of Business.

Schmit, M. J., \& Allscheid, S. P. (1995). Employee attitudes and customer satisfaction: Making theoretical and empirical connections. Personnel Psychology, 48, 521-536.

Schneider, B., \& Bowen, D. E. (1993). The service organization: Human resources management is crucial. Organizational Dynamics, 21(4), 39-52.

Schneider, B., Wheeler, J. K., \& Cox, J. F. (1992). A passion for service: Using content analysis to service climate themes. Journal of Applied Psychology, 77, 705-716.

Schneider, B., White, S. S., \& Paul, M. C. (1998). Linking service climate and customer perceptions of service quality: Test of a causal model. Journal of Applied Psychology, 83, 150-163.

Surprenant, C. F., \& Solomon, M. R. (1987). Predictability and personalization in the service encounter. Journal of Marketing, 51, 86-96.

Wayne, S. J., Shore, L. M., \& Liden, R. C. (1997). Perceived organizational support and leader-member exchange: A social exchange perspective. Academy of Management Journal, 40, 82-111. 


\section{Appendix A}

\section{Listing of the Customer Service Attitude Questions}

\section{Standards for Service Delivery Items}

1. The managers believe that well-trained customer service employees are the key to providing excellent customer service.

2. In the organization I work for, we set very high standards for customer service.

3. Our management believes that no job is so well done that it couldn't be done better.

4. The managers believe that if the workers are happy, excellent customer service will result.

\section{Coworker Support Items}

1. I find my coworkers very helpful in performing my customer service duties.

2. When performing my service duties, I rely heavily on my coworkers.

3. My coworkers provide me with important work-related information and advice that make performing my job easier.

\section{Supervisor Support Items}

1. I find my supervisor very helpful in performing my customer service duties.

2. When performing my service duties, I rely heavily on my supervisor.

3. My supervisor provides me with important work-related information and advice that make performing my job easier.

4. I can count on my supervisor to do the "right thing" when serving customers.

\section{Customer Orientation Items}

1. When performing my job, the customer is most important to me.

2. It is best to ensure that our customers receive the best possible service available.

3. If possible, I meet all requests made by my customers. 
4. As an employee responsible for providing service, customers are very important to me.

5. I believe that providing timely, efficient service to customers is a major function of my job.

\section{Customer Satisfaction With Service Items}

1. Overall, I am happy with the service I just received.

2. The employee(s) who assisted me seemed interested in providing excellent service.

3. The employee(s) who assisted me appeared happy to serve me.

4. The employee(s) performed their duties as I anticipated.

5. The employee(s) who assisted me appeared to be cold and distant.

6. This business's employees really focus on customer service. 


\section{Appendix B}

A Post Hoc Comparison of Coworker and Supervisor Support Versus Perceived Organizational Support

To empirically assess the utility of splitting perceptions of support into two dimensions of coworker and supervisor support, we compared the Survey of Perceived Organizational Support (SPOS; Eisenberger et al., 1986) with our two measures of support in a post hoc model among our sample of 354 line-level service providers. We used the 16-item short form of the SPOS to make this assessment. First, we conducted a principal components factor analysis by using an OBLIMIN rotation, with the 3 coworker support items, the 4 supervisor support items, and the 16 SPOS items. The factor analyses yielded three distinct factors of coworker support, supervisor support, and all 16 SPOS items with no significant crossloadings, indicating that the three factors were indeed distinct. Second, we conducted principalcomponents factor analysis by using a varimax rotation, with the 4 standards for service items, the 5 customer orientation items, and the 16 SPOS items. Again, the factor analyses yielded three distinct factors of coworker support, supervisor support, and the 16 SPOS items with no significant crossloadings, indicating that the three factors were indeed distinct. The reliability of the SPOS was $\alpha=.95$,

$\operatorname{ICC}(1)=.18, \operatorname{ICC}(2)=.56$, and $r_{w g(16)}=.92$. To complete our assessment we then examined the effect of perceived organizational support (POS) in our hypothesized model at the organizational level by substituting the SPOS aggregated to the organizational level for the coworker support and supervisory items to examine the differences in fit across the two models with LISREL. The analyses revealed that coworker support and supervisory support accounted for more variance in the hypothesized model compared with the alternative model using POS. As prior research has suggested (cf. Eisenberger et al., 1990), the alternative model fit the data well, $\chi^{2}(3, N=26)=3.98, p=.26, \mathrm{CFI}=.97, \mathrm{RMR}=.03$, but did not demonstrate a superior fit to the hypothesized model. Standards for service delivery were significantly related to POS $(\beta .=72, p<.01)$ and accounted for $37 \%$ of the variance in POS in the alternative model, whereas coworker and supervisor support accounted for $14 \%$ and $38 \%$ of the variance 
in the hypothesized model, respectively. Likewise, POS was significantly related to customer orientation ( $\beta=.70, p<.01)$ and accounted for $37 \%$ of the variance in customer orientation matching the relationship between coworker support and supervisor support, which accounted for precisely $37 \%$ of the variance in customer orientation in the hypothesized model. The path between customer orientation and customer satisfaction was different across the two models, with customer orientation showing a slightly stronger relationship in the hypothesized model $(\beta=.67, p=.01 ; \beta=.75, p=.01$, for the alternative model and hypothesized model, respectively). POS was not significantly correlated with coworker support $(\mathrm{r}=.30)$ but was significantly correlated with supervisor support $(r=.51, p<.01)$. This set of post hoc analyses determined that POS is not the same as the two support elements we presented and tested here. Although our findings and the findings of Eisenberger et al. (1990) indicate that perceptions of support are ultimately related to better performance, our findings exclusively examine service-based organizations and identify several unique elements in the CSX that suggest a more finite set of support behaviors be considered. 